\title{
Effects of TGF- $\beta 1$ Overexpression on Biological Characteristics of Human Dental Pulp-derived Mesenchymal Stromal Cells
}

\author{
Hasan Salkın ${ }^{1,2,3}$, Zeynep Burçin Gönen ${ }^{3}$, Ergül Ergen ${ }^{4}$, Dilek Bahar ${ }^{3}$, Mustafa Çetin ${ }^{5}$ \\ ${ }^{l}$ Department of Pathology Laboratory Techniques, Vocational School, Beykent University, Büyükçekmece/Istanbul, Turkey \\ ${ }^{2}$ Department of Histology and Embryology, Faculty of Medicine, Erciyes University, Kayseri, Turkey \\ ${ }^{3}$ Oral and Maxillofacial Surgery, Genome and Stem Cell Center, Erciyes University, Kayseri, Turkey \\ ${ }^{4}$ Department of Histology-Embryology, Faculty of Veterinary Medicine, Erciyes University, Kayseri, Turkey \\ ${ }^{5}$ Division of Hematology, Department of Internal Medicine, Faculty of Medicine Erciyes University, Kayseri, Turkey
}

\begin{abstract}
Objective: The aim of our study was to investigate the effect of Transforming growth factor beta-1 (TGF- $\beta 1$ ) gene therapy on the surface markers, multilineage differentiation, viability, apoptosis, cell cycle, DNA damage and senescence of human Dental Pulp-derived Mesenchymal Stromal Cells (hDPSC).

Methods: hDPSCs were isolated from human teeth, and were cultured with $20 \%$ Fetal Bovine Serum (FBS) in minimum essential media-alpha ( $\alpha$-MEM). TGF- $\beta 1$ gene transfer into hDPSCs was performed by electroporation method after the plasmid was prepared. The transfection efficiency was achieved by using western blot and flow cytometry analyses and GFP transfection. Mesenchymal stem cell (MSC) markers, multilineage differentiation, cell proliferation, apoptosis, cell cycle, DNA damage and cellular senescence assays were performed by comparing the transfected and non-transfected cells. Statistical analyses were performed using GraphPad Prism.

Results: Strong expression of TGF- $\beta 1$ in pCMV-TGF- $\beta$ 1-transfected hDPSCs was detected in flow cytometry analysis. TGF- $\beta 1$ transfection efficiency was measured as $95 \%$. Western blot analysis showed that TGF- $\beta 1$ protein levels increased at third and sixth days in pCMV-TGF- $\beta$ 1-transfected hDPSCs. The continuous TGF- $\beta 1$ overexpression in hDPSCs did not influence the immunophenotype and surface marker expression of MSCs. Our results showed that TGF- $\beta 1$ increased osteogenic and chondrogenic differentiation, but decreased adipogenic differentiation. Overexpression of TGF- $\beta 1$ increased the proliferation rate and decreased total apoptosis in hDPSCs $(\mathrm{p}<0.05)$. The number of cells at "S" phase was higher with TGF- $\beta 1$ transfection $(\mathrm{p}<0.05)$. Cellular senescence decreased in TGF- $\beta 1$ transfected group $(\mathrm{p}<0.05)$.

Conclusions: These results reflect that TGF- $\beta 1$ has major impact on MSC differentiation. TGF- $\beta 1$ transfection has positive effect on proliferation, cell cycle, and prevents cellular senescence and apoptosis.
\end{abstract}

Keywords: Dental Pulp-derived Mesenchymal Stem Cells, TGF- $\beta$ 1, Proliferation, Apoptosis, Multilineage differentiation, Gene therapy

Received: July 6, 2018, Revised: July 6, 2018, Accepted: October 31, 2018, Published online: December 31, 2018

Correspondence to Hasan Salkın

Department of Medical Services and Techniques, Programme of Pathology Laboratory Techniques, Vocational School, Beykent University, Büyükçekmece/Istanbul 34550, Turkey

Tel: +90-530-125-5808, Fax: +90-212-872-2830

E-mail: hasansalkin@beykent.edu.tr

(c) This is an open-access article distributed under the terms of the Creative Commons Attribution Non-Commercial License (http://creativecommons.org/ licenses/by-nc/4.0/), which permits unrestricted non-commercial use, distribution, and reproduction in any medium, provided the original work is properly cited. Copyright (c) 2019 by the Korean Society for Stem Cell Research 


\section{Introduction}

Mesenchymal Stromal Cells (MSCs) are multipotent stem cells with a superior capacity for self-renewal, and are capable of differentiating into adipocytes, osteoblasts, chondrocytes $(1,2)$. In these days, MSCs have been broadly used in regenerative medicine (3). Dental Pulp-derived Mesenchymal Stem Cells (DPSCs) have become a popular research topic in that they are similar to other mesenchymal stem cells, easy to obtain and are used in regenerative medicine and tissue engineering (4). In vitro and in vivo studies have been previously performed to understand the biology of DPSCs. The first study in this area were performed with stem cells obtained from the pulp of wisdom teeth by Gronthos et al. (2000). These cells differentiated into dentin or pulp-like structures (5). Later, the same researchers reported that they obtained stem cells from exfoliated deciduous teeth (6). DPSCs differentiate to many cell types, and their multipotent properties have been compared with Bone Marrow Stem Cells (BMSCs) (7). The proliferation, availability and cell counts of DPSCs were reported to be higher when compared to BMSCs (8). DPSCs differentiate into adipogenic osteogenic and chondrogenic cell lines; besides epithelial cells, they also have the ability to differentiate into neural and vascular cells. They express the cytokeratin-18 and 19, which are epithelial markers (9). The differentiation of mesenchymal stem cells usually involves the use of signaling factors as recombinant proteins or gene therapy that can functionally activate genes (10). Transforming Growth Factor Beta 1 (TGF- $\beta 1$ ) activates mainly SMAD transcription factors with complex cellular responses (11). It has great effect on a multiplicity of other pathways such as Mitogen-Activated Protein Kinase (MAPK), Jun N-terminal Kinase (JNK), and the phosphatidylinositol 3-kinase/Akt/mTOR pathways $(12,13)$. TGF- $\beta 1$ also up-regulates the cyclin-dependent kinase inhibitors $(14,15)$. In point of this variation of implications on the molecular network, it may be not surprising that the effects of TGF$\beta 1$ are mainly related with the cell type, the cellular niche and the differentiation state $(16,17)$. Upon TGF- $\beta$ binding to its specific receptor, a heterotetrametric receptor complex of two Type-I (T $\beta$ RI) and two Type-II receptors (T $\beta$ RII) are formed; then constitutively active $\mathrm{T} \beta$ RII phosphorylates activates $\mathrm{T} \beta \mathrm{RI}$ (18). The activated serine/threonine kinase $\mathrm{T} \beta \mathrm{RI}$ phosphorylates the specific receptor-regulated SMADs (R-SMADs) SMAD2 and SMAD3, which form hetero-oligomers with the co-SMAD SMAD4. They translocate from the cytoplasm to the nucleus, where they regulate transcription of target genes
$(19,20)$. Senescence would result in a stable cell cycle arrest and, MSCs lose their self-renewal ability (21). The superior proliferative ability and regenerative potential are primary phenotypes of MSCs (22). Loss of therapeutic potential would limit their utilization in transplantation medicine. TGF- $\beta 1$ has been reported to induce senescence in some tumor cells $(23,24)$. However, whether TGF- $\beta$ affects senescence of DPSCs has still not been elucidated. Also, the effects on apoptosis, cell cycle and DNA damage of DPSCs of TGF- $\beta 1$ overexpression have not been investigated yet. The aim of our study is to investigate the surface markers, multilineage differentiation, viability, apoptosis, cell cycle, DNA damage and senescence of Human Dental Pulp-Derived Mesenchymal Stromal Cells (hDPSC) which transfected by TGF- $\beta 1$ gene.

\section{Materials and Methods}

\section{Isolation and Culture of hDPSCs}

hDPSCs were obtained from Erciyes University Genome and Stem Cell Center, Kayseri, Turkey. The cells were thawed rapidly in a 37-degree water bath, and were transferred into plates at a density of 5,000 cells $/ \mathrm{cm}^{2}$ in $\alpha$-MEM (Biological Industries, Beit-Haemek, Israel) supplemented containing $2 \mathrm{mM}$ L-glutamine (Gibco, USA), $100 \mathrm{U} / \mathrm{ml}$ penicillin, $100 \mu \mathrm{g} / \mathrm{ml}$ streptomycin (Lonza, MD, USA), 20\% Fetal Bovine Serum (Biological Industries, Beit-Haemek, Israel) and $100 \mu \mathrm{M}$ L-ascorbic acid 2-phosphate (Sigma-Aldric, USA). All the cell cultures were maintained at $37^{\circ} \mathrm{C}$ in a humidified atmosphere containing 5\% CO2. The culture medium was changed every $2 \sim 3$ days, and the cell cultures were monitored regularly under an inverted microscope (Leica). When the cells reached $70 \% \sim 80 \%$ confluence, they were harvested by using $0.05 \%$ Trypsin/EDTA (Lonza, MD, USA) and were sub-cultured for further experiments.

\section{Preparation of $p C M V$-TGF- $\beta$ 1-ha Plasmid}

The plasmid TGF- $\beta 1$ (Sino Biological Inc, China) was amplified in Escherichia coli host strain DH5 $\alpha$, and was purified by plasmid isolation with the Endo-Free Maxiprep Plasmid Isolation Kit (Qiagen, Germany) according to the manufacturer's protocol. Ampicillin was used to select plasmid TGF- $\beta 1$ ( $p C M V-T G F-\beta 1-h a)$ - transformed cells. The DNA concentration was detected by measuring the UV absorbance at $260 \mathrm{~nm}$ with an ultraviolet spectrophotometer. UV spectroscopy showed that the A260/A280 absorbance was between 1.8 and 1.9, which indicated that no protein or RNA was present. The detailed information regarding the structure of plasmid TGF- $\beta 1$ and agarose 
gel electrophoresis imaging are shown in Fig. 1.

\section{TGF- $\beta 1$ Gene Transfection}

The transfection procedure was performed as follows:
TGF- $\beta 1$ gene transfer into hDPSCs was performed by electroporation method after the plasmid was prepared. The stem cells were incubated in 20\% FBS and $2 \mathrm{mM}$ glutamine supplemented with $\alpha-M E M$ and at $37^{\circ} \mathrm{C}$ in an in-
Morphology of hDPSCs

A

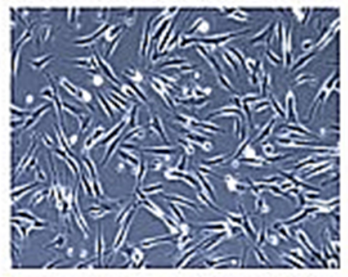

Morphology of TGF $\beta 1$ transfected hDPSCs

B

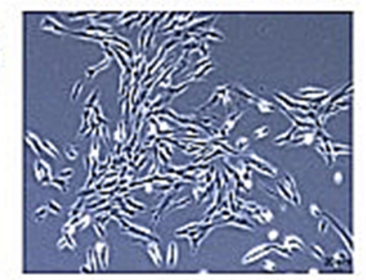

$1200 \mathrm{v}, 20 \mathrm{~ms}$, 1pulse pCMV-GFP transfection

C

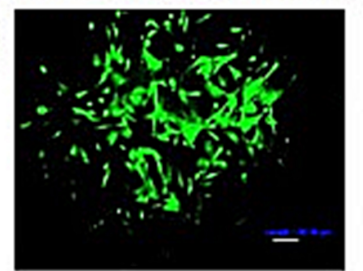

D
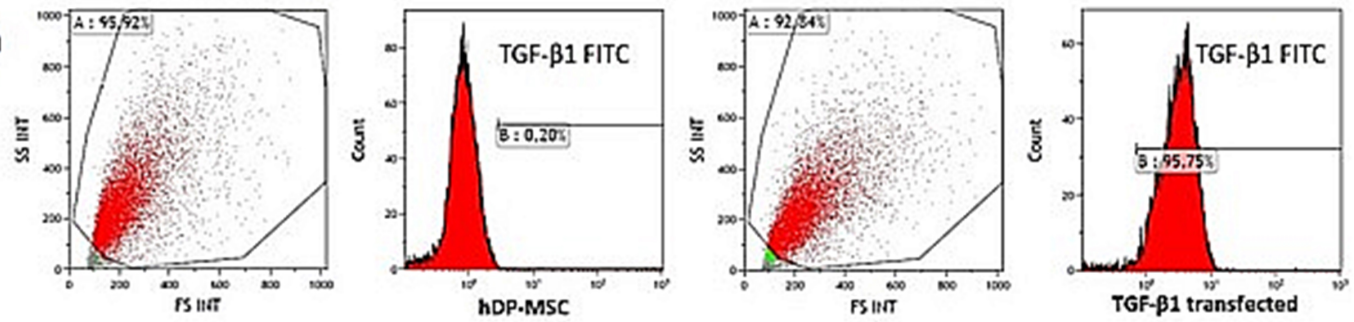

$\mathbf{E}$

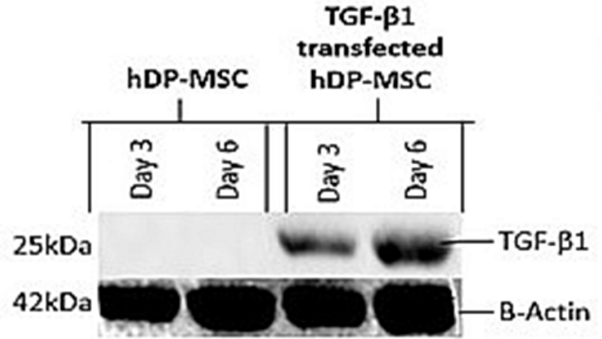

$\mathrm{F}$
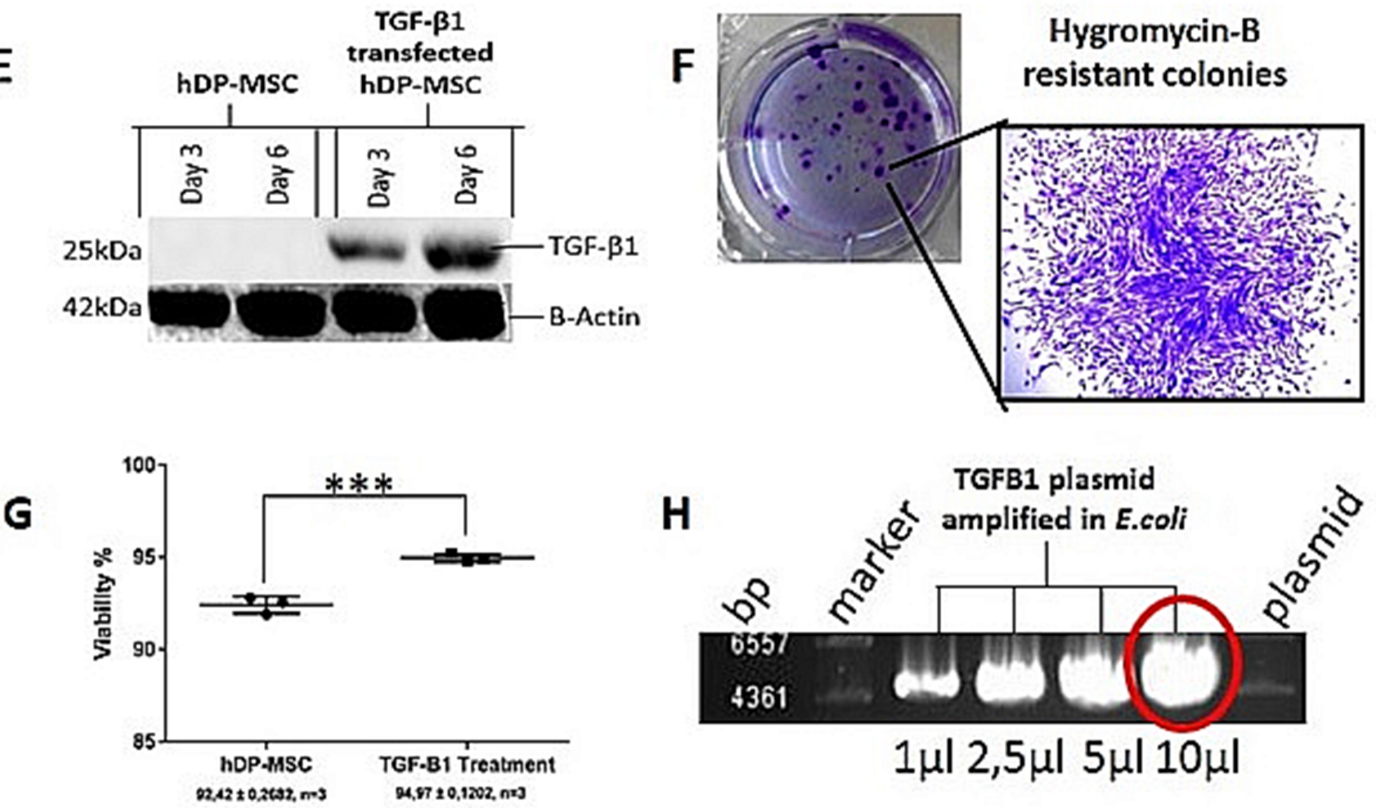

$1 \mu \mathrm{l} 2,5 \mu \mathrm{l} 5 \mu \mathrm{l} 10 \mu \mathrm{l}$

Fig. 1. Continuous overexpression of TGF- $\beta 1$ in hDPSCs and morphology in monolayer culture. Morphology of non-transfected hDPSCs (A) and TGF- $\beta 1$ transfected hDPSCs under inverted microscope (Leica, Germany) (B). Fluorescence microscope examination showing the efficiency after pCMV-GFP transfection with 1,200 v, $20 \mathrm{~ms}$, 1pulse (C). After transfection at $48 \mathrm{~h}$, flow cytometry analysis for TGF $\beta 1$ expression between non-transfected hDPSCs and TGF- $\beta 1$ transfected hDPSCs. Transfection efficiency was found 95\% (D). Western blot analysis for TGF- $\beta 1$ protein detection after transfection. TGF- $\beta 1$ protein increasing at 3 and 6 days in TGF $\beta 1$ transfected hDPSCs (E). Hygromicin-B resistant TGF- $\beta 1$ transfected hDPSCs (F). Viability test between non-transfected hDPSCs and TGF- $\beta 1$ transfected hDPSCs with Count \& Viability assay kit (Muse, Millipore, USA), The values shown are the means \pm SD from three independent experiments, ${ }^{* * *} \mathrm{p}=0.0005$ (G). Agarose gel electrophoresis of $\mathrm{pCMV}-\mathrm{TGF} \beta 1$ plasmid DNA amplified in E.coli DH5 $\alpha$ before transfection into hDPSCs. Red ring shown that used for transfection into hDPSCs $(\mathrm{H})$. Microscope magnification are 10x and scale bar is $20 \mu \mathrm{m}$ for figure $1 \mathrm{~A}$ and 1B. For figure 1C microscope magnification is $20 \times$, scale bar is $50 \mu \mathrm{m}$. 
cubator containing 5\% CO2. The cells were centrifuged at $350 \mathrm{~g}$ for $5 \mathrm{~min}$, the collected cells were resuspended in $\mathrm{Ca}^{2+}$ and $\mathrm{Mg}^{2+}$-free PBS and washing process was completed. The $1 \times 10^{6}$ cells were resuspended in $45 \mu 1$ Neon buffer $\mathrm{R}$ and $5 \mu \mathrm{l}$ of TGF- $\beta 1$ plasmid containing $1 \mu \mathrm{g} / \mathrm{ml}$ DNA was added on the cells. DPSCs were transfected with pCMV-TGFB1-ha (Sino Biological Inc, China) by using Neon Transfection System (Invitrogen, USA).

\section{The Culture Conditions of TGF- $\beta 1$ Transfected hDPSCs}

After TGF- $\beta 1$ gene transfection was performed according to the specified procedure, these cells were cultured in an incubator that had $5 \% \mathrm{CO}_{2}$ and $95 \%$ humidity in $\alpha$-MEM with $20 \%$ FBS without containing hygromycin selective antibiotics for 48 hours recovery. After 48 hours, TGF- $\beta 1$ was cultured in broth medium that had $50 \mu \mathrm{g} / \mathrm{ml}$ hygromycin on TGF- $\beta 1$ transfected cells. The cells were selected for 2 weeks by changing the broth medium every three days with a broth medium that had Hygromycin; and it was made sure that TGF- $\beta 1$ plasmid was transferred to the chromosome in a stable way. On the second day of the culture, the TGF- $\beta 1$ expression was measured with flow cytometry analysis in the transfected cells. On the $3^{\text {rd }}$ and $6^{\text {th }}$ days, the TGF- $\beta 1$ protein expressions were analyzed with western blot analysis. Some of the cells that were selected for 14 days were seeded as 100 cells/ $\mathrm{cm}^{2}$, and the CFU-F test was performed; and the hygromycin-resistant TGF- $\beta 1$ transfected hDPSC colonies were visualized with crystal violet. When it was proven that the TGF- $\beta 1$ transfection was performed successfully, the positive and negative MSCs markers and the surface marker expressions of the cells were analyzed with flow cytometry; and adipogenic, osteogenic and chondrogenic differentiation tests were carried out on these cells.

\section{Western Blot for TGF- $\beta 1$ Protein Detection}

For western blot analyses, 3 and 6-day transfected cells and non-transfected cells were used. Total protein was extracted with RIPA buffer (10 mM Tris-HCl, pH 7.8, 1\% NP-40, 0.1\% Na-deoxycholate, $150 \mathrm{mM} \mathrm{NaCl}, 1 \mathrm{mM}$ EDTA, $1 \mathrm{mM}$ PMSF, $1 \mathrm{mg} / \mathrm{ml}$ each of aprotinin, leupeptin and pepstatin, $1 \mathrm{mM} \mathrm{Na} \mathrm{VO}_{4}$ and $1 \mathrm{mM} \mathrm{NaF}$ ) on ice. From each protein sample, $50 \mu 1$ was denaturated for 5 minutes at $95^{\circ} \mathrm{C}$ in the loading buffer that contained Tris, glycerol, SDS, B-mercaptoethanol. Protein samples were loaded and separated by 12\% SDS-polyacrylamide gel electrophoresis. Then the separated proteins were transferred to a PVDF membrane (BioRad, USA) in a semi-dry transference system (BioRad, the USA). After that, the membrane was incubated in TBS-t buffer (BioRad, USA) blocked in blocking solution $(0.25 \%$ Tropix I Block) for 1 hour at room temperature, and was then incubated with anti-TGFB1 primary antibody (Cell Signaling, USA) $1: 1000$ in blocking solution overnight at $+4^{\circ} \mathrm{C}$. Then the membrane was washed in TBS-t 3 times for 30 minutes, and was incubated with HRP conjugated secondary antibody (Dako, USA) $1: 1000$ in blocking solution for 1 hour at room temperature. After washing, the membrane was treated with ECL Solution (Thermo Scientific, the USA), and the exposed bands were scanned by imagining system (BioRad, USA).

\section{Flow Cytometry for TGF- $\beta 1$ Protein Expression}

The cells that were transfected for two days and -as a control group- non-transfected cells were used for flow cytometry analyses. Harvested cells were washed twice with PBS, and were fixed with $1 \%$ paraformaldehyde for $10 \mathrm{mi}$ nutes at room temperature. Then the cells were washed and permeabilized with $0.5 \%$ Tween 20 for 5 minutes. After the washing step, the cells were incubated with anti-TGF- $\beta 1$ primary antibody (Cell Signaling, USA) $1: 50$ in $1 \%$ Ig-G free BSA (Sigma) for 45 minutes at $37^{\circ} \mathrm{C}$. After the incubation, the cells were incubated with Fitc conjugated secondary antibody (Abcam, UK) $1: 100$ in 1\% BSA for 1 hour at room temperature. Then, the cells were washed again by centrifugation and analyzed by flow cytometry Navios (Beckman Coulter, USA). The cells were first gated on the basis of light-scatter properties to screen out debris; and cells surface phenotypes were verified through antibody. The data were analyzed with KALUZA software (Beckman Coulter, USA). More than 50\% staining was regarded as positive.

\section{Immunophenotypic Characteristics of Experiment Groups}

Expression of a panel of surface markers was analyzed in hDPSCs upon expansion for 3 passages with or without TGF- $\beta 1$ transfected. The cells were stained in parallel with the following monoclonal mouse antihuman antibodies: CD90-FITC, CD44-PE, CD105 PerCP5.5, CD73APC, CD34-FITC, CD45-PE, CD11b-PerCP5.5, HLA-DRAPC (BD Bioscience, Heidelberg, Germany). Then, the cells were washed again by centrifugation, and were analyzed by flow cytometry Navios (Beckman Coulter, USA). The cells were first gated on the basis of light-scatter properties to screen out debris; and cells surface phenotypes were verified through antibody. The data were analyzed with KALUZA software (Beckman Coulter, the USA). More than $50 \%$ staining was regarded as positive. 


\section{Adipogenic Differentiation}

TGF- $\beta 1$ transfected hDPSCs and non-transfected hDPSCs from passage three $\left(3,000\right.$ cells $\left./ \mathrm{cm}^{2}\right)$ were seeded in 6-well plates to induce adipogenic differentiation. When they reached $90 \sim 100 \%$ confluency, the growth medium on the cells was replaced with adipogenic differentiation medium. For this, hMSC adipogenic induction medium (Lonza, MD, USA) and adipogenic maintain medium (Lonza, MD, USA) were used. Firstly, the cells were cultured for 3 days with induction medium (induction medium contained adipogenic basal medium, 10\% FBS, 0.5 $\mathrm{mM}$ isobutyl-methylxanthine (IBMX), $10^{-6} \mathrm{M}$ dexamethasone, $10 \mu \mathrm{g} / \mathrm{ml}$ insulin, $200 \mu \mathrm{M}$ indomethacin, and $1 \%$ antibiotic/antimycotic). Next, they were cultured for 3 days with adipogenic maintain medium (maintain medium contained adipogenic basal medium, $10 \mu \mathrm{g} / \mathrm{ml}$ insulin, $10 \% \mathrm{FBS}$ and $1 \%$ antibiotic/antimycotic. This cycle was repeated 3 times for 21 days and replaced with a fresh medium every three days; and was stimulated for 21 days. The presence of intracellular lipid droplets, which indicates adipogenic differentiation was confirmed by AdipoRed Assay Kit (Lonza MD, USA).

\section{Osteogenic Differentiation}

TGF- $\beta 1$ transfected hDPSCs and non-transfected hDPSCs in $\mathrm{P} 3$ were seeded on $0.1 \%$ gelatin coated 12 -well plate $\left(3,000 \mathrm{cells} / \mathrm{cm}^{2}\right)$; and 24 hours later, the growth medium was replaced with hMSC Osteogenic differentiation medium (Lonza, MD, USA) and the medium was replaced twice a week. Osteogenic differentiation medium contained $100 \mathrm{nM}$ dexamethasone, $0.05 \mu \mathrm{M}$ ascorbate-2-phosphate, $10 \mathrm{mM} \beta$-glycerophosphate, $1 \%$ antibiotic/ antimycotic and 10\% FBS. At the end of the second week, calcium storage in differentiated cells was demonstrated by staining with $1 \%$ alizarin red.

\section{Chondrogenic Differentiation}

For chondrogenic differentiation, TGF- $\beta 1$ transfected hDPSCs and non-transfected hDPSCs in P3 were seeded on 12-well plate (250,000 cells/well) using micromass culture technique. After $24 \mathrm{~h}$, the growth medium was replaced with hMSC Chondrogenic differentiation medium (Lonza, MD, USA) and was stimulated for 24 days by replacing with fresh medium twice a week. Chondrogenic differentiation kit contained chondrogenic basal differentiation medium supplemented by dexamethasone, ITSpremix, pyruvate, ascorbate-2-phosphate, proline, gentamicin-amphotericin-1000 (GA-1000) and $10 \mathrm{ng} / \mathrm{ml}$ TGF$\beta 3$. At the end of 24 days, the extracellular matrix components in differentiated cells was demonstrated by staining with safranin-O.

\section{Cell Proliferation Assay}

In order to determine the proliferation rate of TGF- $\beta 1$, transfected DPSCs and non-transfected DPSCs in culture, a 3-(4,5-dimethylthiazol-2-yl)-2,5-diphenyltetrazolium bromide (MTT) assay was performed. The cells were seeded at 5,000 cells $/ \mathrm{cm}^{2}$ in a 96-well plate in standard DPSC culture medium. All conditions were performed in triplicate. After day 1, day 2, day 3, day 4 and day 5 of culturing, the culture medium was replaced with $500 \mu \mathrm{g} / \mathrm{ml}$ MTT in standard DPSC culture medium containing $20 \%$ FBS. Following $4 \mathrm{~h}$ of the incubation, the MTT solution was removed and dimethylsulfoxide was added to dissolve the formed formazan. The absorbance was measured at a wavelength of $560 \sim 750 \mathrm{~nm}$ with a Glomax Multi Detection System microplate reader (Promega, USA).

\section{Annexin V \& Dead Cell Assay for Apoptosis}

Apoptotic cells were detected by using a fluorescein conjugated annexin V kit on a Muse EasyCyte flow cytometer following the manufacturer's instructions.

\section{Cell Cycle Assay}

For each assay, the cells were collected, fixed in $70 \%$ ethanol, washed with PBS, and dissolved in a hypotonic buffer containing propidium iodide. The samples were collected using a flow cytometer (Muse EasyCyte, Merck Millipore, Germany), and were analyzed with EasyCyte software according to the standard procedure.

\section{DNA Damage Assay}

To determine the DNA damage in TGF- $\beta 1$ transfected and non-transfected hDPSCs the H2A.X Activation Dual Detection Kit, which included two directly conjugated antibodies, was used (Muse, Merck Millipore, Germany). A phospho-specific anti-phospho-Histone H2A.X (Ser139)Alexa Fluor ${ }^{\circledR} 555$ and an anti-Histone H2A.XPECy5 conjugated antibody was used to measure the total levels of Histone H2A.X. The samples were collected using a flow cytometer (Muse EasyCyte, Merck Millipore, Germany), and were analyzed with EasyCyte software according to the standard procedure.

\section{$\beta$-galactosidase Assay for Senescence}

The experiments were performed according to the manufacture's protocol of the $\beta$-galactosidase assay kit (Promega) for TGF- $\beta 1$ transfected hDPSCs and non- transfected hDPSCs on the $7^{\text {th }}$ day. Briefly, cell lysates were prepared with $1 \times$ reporter lysis buffer (RLB); and $150 \mu 1$ 
of lysates were added into each well; and then, $150 \mu 1$ Assay $2 \times$ buffer was added into each well. The incubated reactions were continued at $37^{\circ} \mathrm{C}$ until a faint yellow color developed. The reaction was stopped by adding $150 \mu 1$ of $1 \mathrm{M}$ sodium carbonate. The absorbance was read at 420 $\mathrm{nm}$.

\section{Statistical analysis}

Statistical analyses were performed using GraphPad Prism version 6.00 for windows (GraphPad Software, San Diego California, the USA). A two-tailed, unpaired Student's $t$-test was applied for analyzing the difference between average responses of TGF- $\beta 1$ transfected hDPSCs and non-transfected hDPSCs. Three levels of significance were considered: ${ }^{*} \mathrm{p}<0.05,{ }^{* *} \mathrm{p}<0.01$, and ${ }^{* * *} \mathrm{p}<0.001$.

\section{Results}

\section{Culture of hDPSCs}

The best part of hDPSCs after isolated by enzymatic digestion was attached to culture flasks, and the majority of the cells displayed a fibroblast-like, spindle-shaped morphology during the early days of incubation. These cells began to proliferate after $2 \sim 3$ days of incubation. After plating for $10 \sim 12$ days, these primary cells reached $80 \%$ confluence during their first passage. During their later passages, there were no changes in the morphology and growth in the majority of these hDPSCs (Fig. 1A).

\section{Transfection Efficiency}

To determine the efficiency of TGF- $\beta 1$ gene transfection into hDPSCs, pCMV-GFP was transfected into hDPSCs at various electroporation parameters. GFP-positive hDPSCs were quantified under a fluorescence microscope 3 days after transfection. Optimal transfection efficiency was obtained at 1,200 v, $20 \mathrm{~ms}, 1$ pulse (Fig. 1C). Considering this transfection efficiency, 1,200 v, $20 \mathrm{~ms}, 1$ pulse was selected for the transfection of pCMV-TGF $\beta 1$. Flow cytometry analysis detected strong expression of TGF- $\beta 1$ in pCMV-TGF- $\beta 1$-transfected hDPSCs. TGF$\beta 1$ transfection efficiency was measured as 95\% (Fig. 1D). Also, western blot analysis showed that TGF- $\beta 1$ protein levels increased on the third and sixth days in pCMV-TGF- $\beta$ 1-transfected hDPSCs (Fig. 1E). To select the TGF- $\beta 1$, transfected hDPSCs in monolayer culture were used $75 \mu \mathrm{g} / \mathrm{ml}$ Hygromycin B (Sigma-Aldrich, USA) and hygromycin resistant colonies (Fig. 1B) were stained with $0.05 \%$ crystal violet (Sigma-Aldrich, USA) (Fig. 1F).

\section{Immunophenotypic Analyses}

To investigate immunophenotype of TGF- $\beta 1$ transfected DPSCs and non-transfected DPSCs, we characterized MSC-specific markers via flow cytometer analysis. Both groups at passage 3 revealed the similar typical immunophenotype (CD11b-, CD34-, CD45-, HLA DR-, $\mathrm{CD} 90+, \mathrm{CD} 105+, \mathrm{CD} 44+, \mathrm{CD} 73+)$ of MSC no matter whether they were cultured with or without continuous TGF- $\beta 1$ overexpression for 7 days (Fig. 1C). These re-

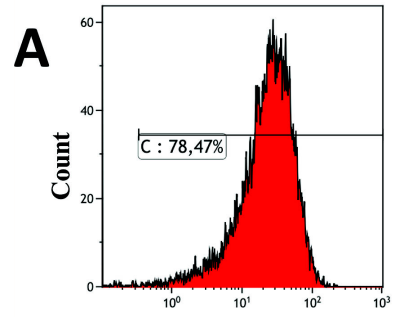

CD44

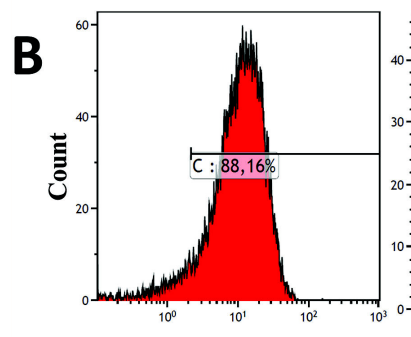

CD44

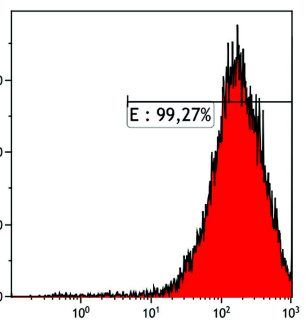

CD73

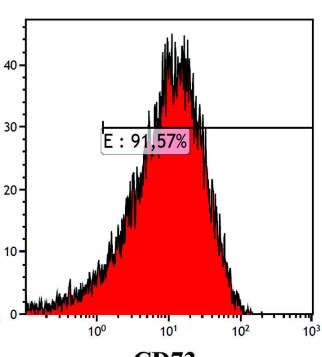

CD73

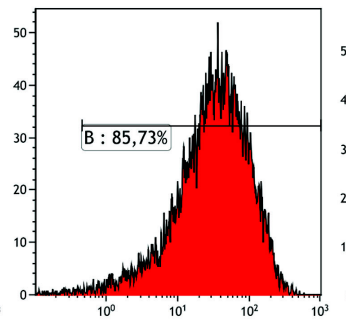

CD90

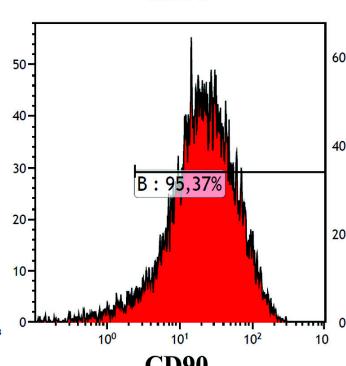

CD90
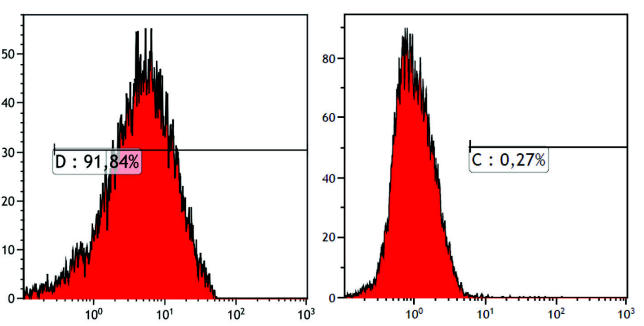

Negative cocktail markers

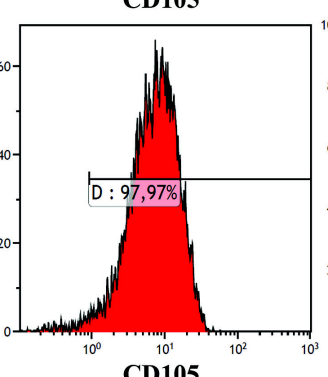

CD105

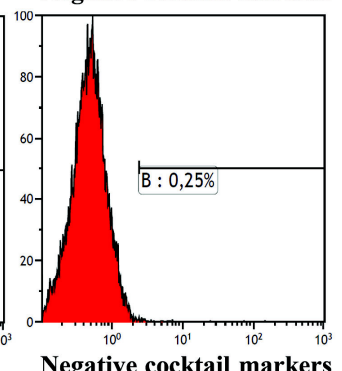

Fig. 2. Flow cytometer analysis showed that non-transfected DPSCs (A) and TGF- $\beta 1$ transfected DPSCs (B) were positive for CD90, CD44, CD105 and CD73, which are MSC specific markers and were negative for CD34, CD45, CD11b and HLA-DR, which are hematopoietic stem cell. 
sults indicate that continuous TGF- $\beta 1$ overexpression in hDPSCs did not influence the immunophenotype and surface marker expression of MSCs (Fig. 2).

\section{Differentiation of hDPSCs after gene transfer of TGF- $\beta 1$}

At the third passage of TGF- $\beta$ 1, the adipogenic, osteogenic and chondrogenic differentiation abilities of the transfected DPSCs and non-transfected DPSCs were assessed. It was observed that the cells accumulated calcium deposits during the osteogenic differentiation of the cells; and it was determined that osteogenic differentiation occurred in both groups after osteogenic medium treatment for 14 days, and calcium deposits was demonstrated by positive alizarin red staining. However, mineralization and differentiation in TGF- $\beta 1$ transfected cells were observed remarkably more compared to non-transfected cells (Fig. 3A). Chondrogenic differentiation was evaluated by histological staining. Chondrogenic medium-treated cells formed aggregates in monolayer culture. It was determined with safranin-o positive staining that more extracellular matrices were formed in the TGF- $\beta 1$ trans- fected DPSCs at the end of 21 days compared to nontransfected DPSCs (Fig. 3B). It was shown with adipored staining that the lipid droplets and triglycerides increased in the cells treated with adipogenic medium for 21 days (Lonza, MD, USA). Our results showed that TGF- $\beta 1$ increased osteogenic and chondrogenic differentiation, but reduced adipogenic differentiation (Fig. 3C). These results reflect that TGF- $\beta 1$ has major impact on MSC differentiation.

\section{Overexpression of TGF- $\beta 1$ increases proliferation of DPSCs}

To analyze the impact of TGF- $\beta 1$ gene transfection on proliferation of hDPSCs, we performed gene transfer into cells. Then, MTT assay was designed for five days after transfection between non-transfected and transfected cells. For the first 4 days, compared to controls (non-transfected cells), proliferation significantly increased in TGF- $\beta 1$ transfected cells $(p<0.05)$. But significant difference was not found only on the $5^{\text {th }}$ day between the groups (Fig. $4 \mathrm{~A})$.
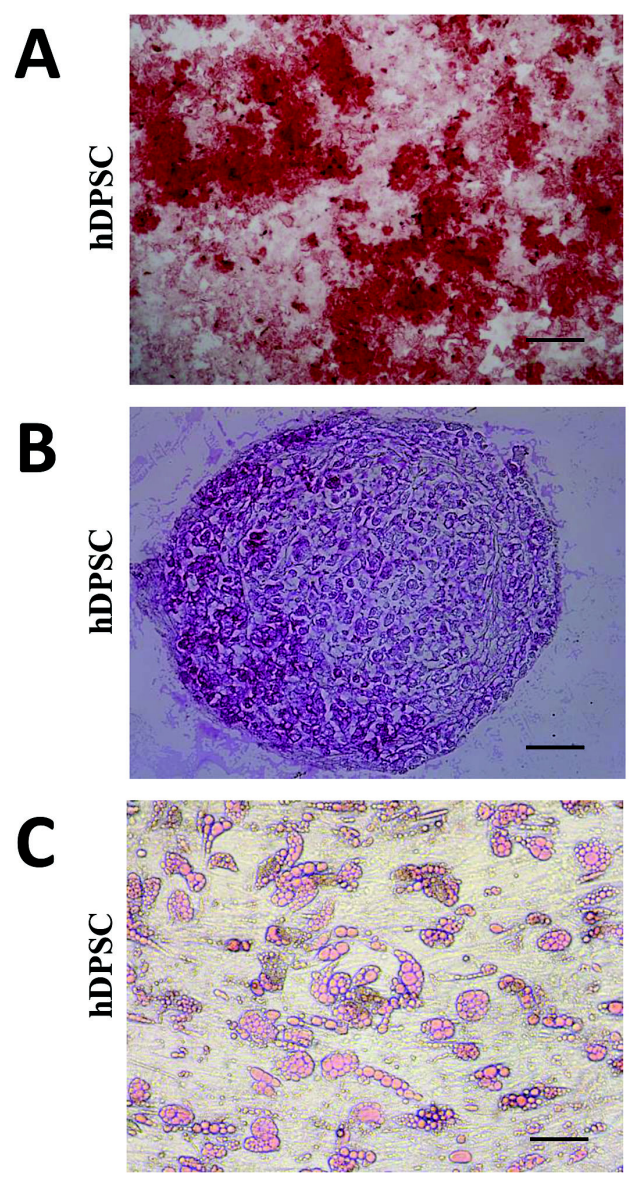
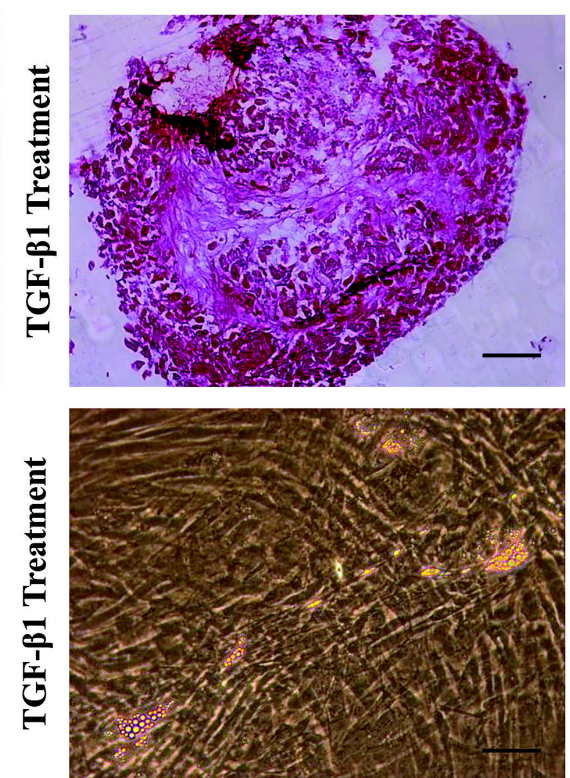

Fig. 3. Osteogenic and chondrogenic differentiation was increased remarkable by overexpression of TGF- $\beta 1$ in DPSCs. However, adipogenic differentiation was reduced significantly in TGF- $\beta 1$ transfected DPSCs compare with non-transfected hDPSCs. Particularly adipogenic differentiation was impaired by TGF- $\beta$ 1. Osteogenic differentiation and alizarin red staining $(\mathrm{A})$, Chondrogenic differentiation and safranin-o staining (B), Graphic show adipored assay fluorimetric measurement results for adipogenic differentiation (C). Microscope magnifications are $4 \times$. Scale bar is $100 \mu \mathrm{m} .{ }^{*} \mathrm{p}<0.05$. 


\section{Early and late apoptosis decreased in TGF- $\beta 1$ transfected hDPSCs}

After 7 days of TGF- $\beta 1$ transfection, early apoptosis was measured as $2.267 \pm 0.02 \%(\mathrm{n}=3, \mathrm{p}=0.0006)$, late apoptosis was measured as $2.633 \pm 0.1 \%(\mathrm{n}=3, \mathrm{p}=0.0132)$, and total apoptosis was measured as $4.90 \pm 0.12 \%(n=3$, $\mathrm{p}=0.0004)$ in TGF- $\beta 1$ transfected cells. In non-transfected hDPSCs, early, late and total apoptosis values were measured as $4.267 \pm 0.21 \%(n=3), 3.250 \pm 0.11 \%(n=3)$ and $7.467 \pm 0.21(n=3)$, respectively (Fig. $4 B \sim D)$.

\section{Cell Cycle, H2AX Activation and $\beta$-galactosidase Assay}

TGF- $\beta 1$ transfection increased the number of cells at " $S$ " phase $(\mathrm{p}<0.05)$. There was no significant difference at DNA damage. Cellular senescence decreased in TGF- $\beta$ 1 transfected group $(\mathrm{p}<0.05)$ (Fig. 5).

\section{Discussion}

The effects of TGF- $\beta 1$ are dependent on a diversity of several parameters such as culture media, pretreatment, incubation time, cell type and differentiation (25). One of these differences is also shown in this study by transmission into MSCs of TGF- $\beta 1$ with gene transfer. The aim of this study was to investigate the effect of TGF- $\beta 1$ gene therapy on the surface markers, multi lineage differentiation, viability, apoptosis, cell cycle, DNA damage and senescence of hDPSC. On the other hand, according to our study results, we think that TGF- $\beta 1$ overexpression with gene transfer may improve the biological potentials of the MSCs and can be a option instead of transmission of recombinant protein into cell from outside. Our results showed that TGF- $\beta 1$ has no impact on MSC immunophenotype; however, there was increased growth and differentiation; and there was no evidence that it induces cellular senescence and apoptosis. The MSCs were compared on the basis of their morphological properties, proliferation rates, expression of common MSC markers such as positive $\mathrm{CD} 90, \mathrm{CD} 105, \mathrm{CD} 44, \mathrm{CD} 73$ and negative CD34, CD45 and in vitro differentiation potentials into adipocytes, osteoblasts, and chondrocytes (26). A combination of TGF- $\beta 1$, PDGF, and $\beta$-FGF was sufficient to
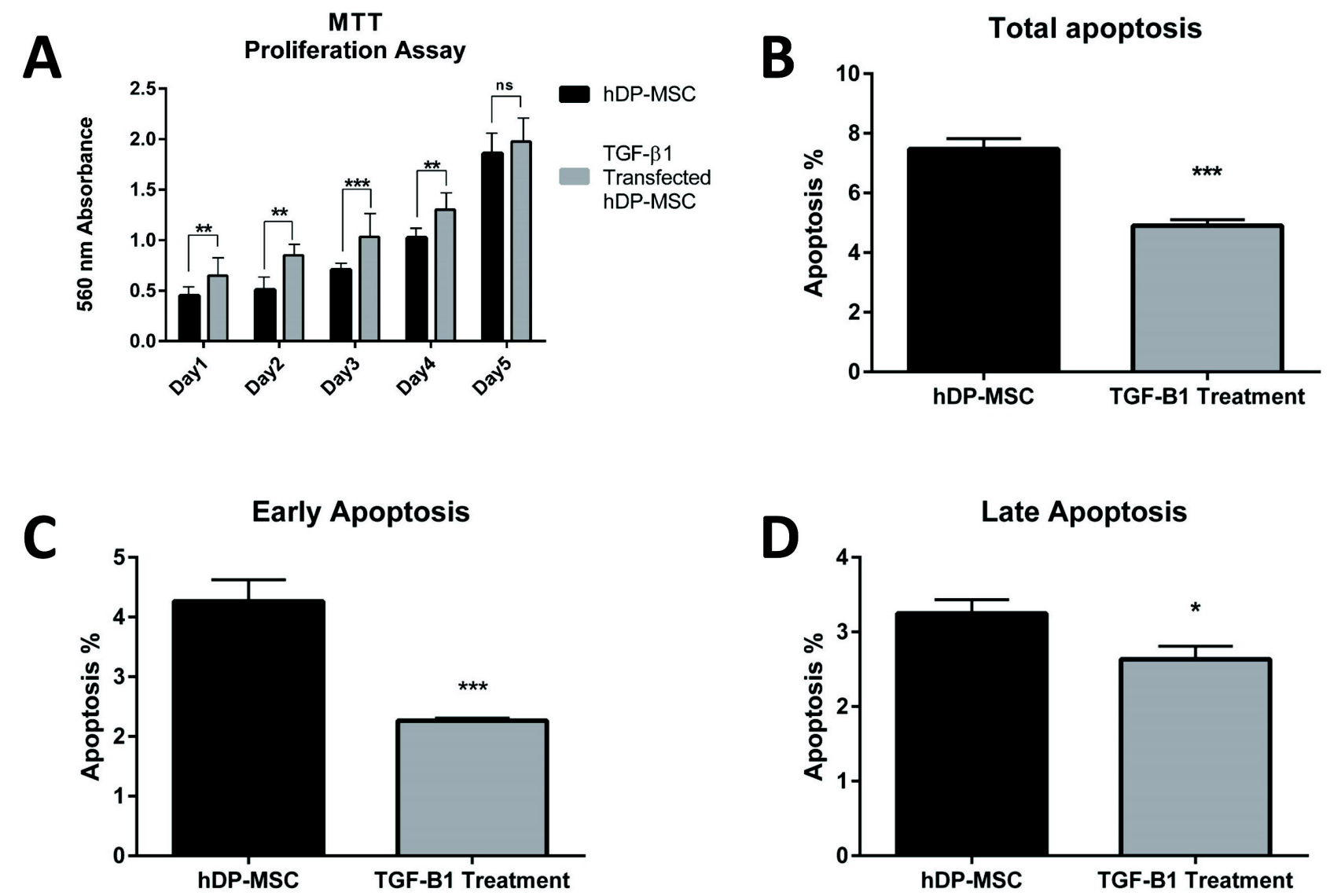

Fig. 4. MTT assays results for 5 days were shown that proliferation significantly increased in TGF- $\beta 1$ transfected cells $(p<0.05)(A)$. Early, late and total apoptosis results between TGF- $\beta 1$ transfected hDPSCs and non-transfected hDPSCs at 7 days, $\mathrm{n}=3, \mathrm{p}<0.05$ (B D). 


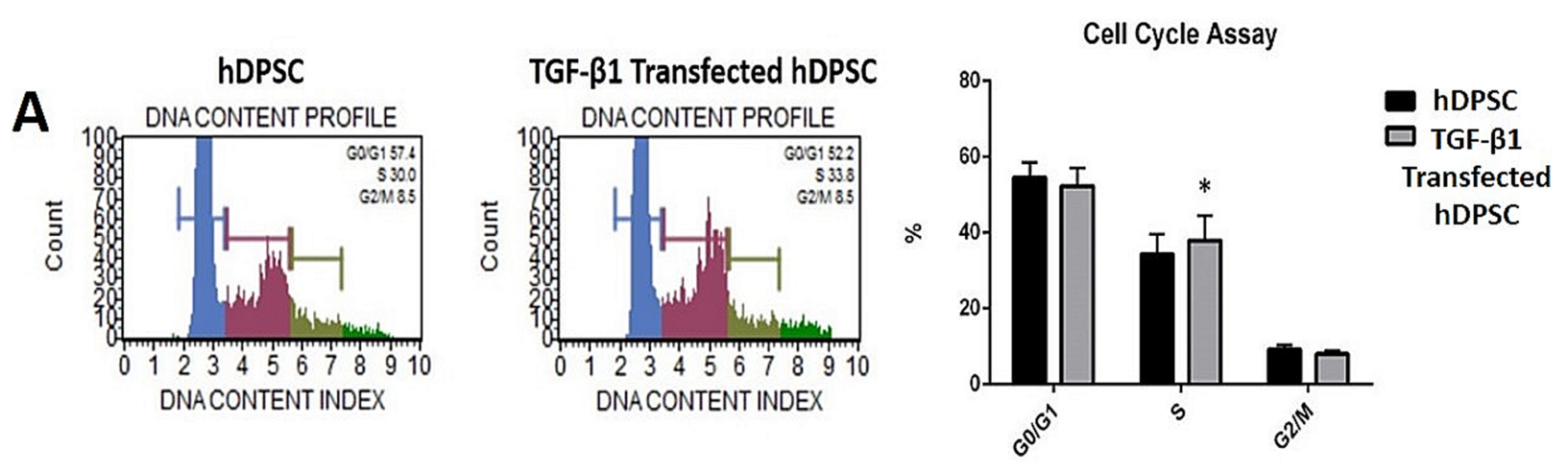

hDPSC

B

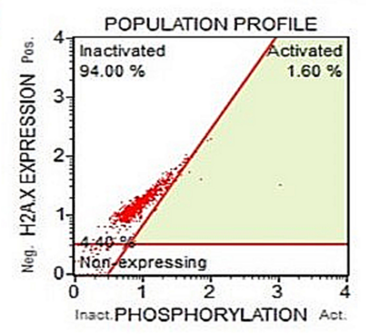

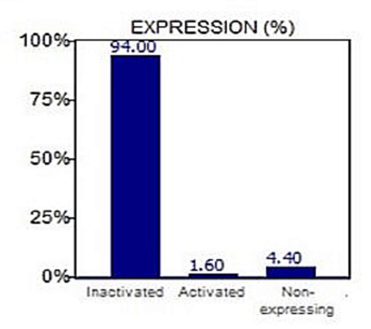

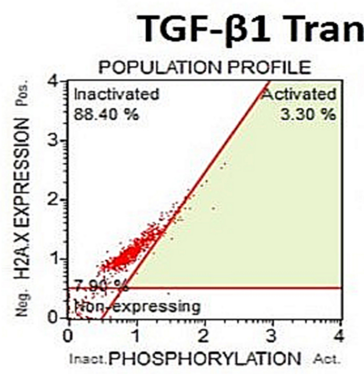

TGF- $\beta 1$ Transfected hDPSC

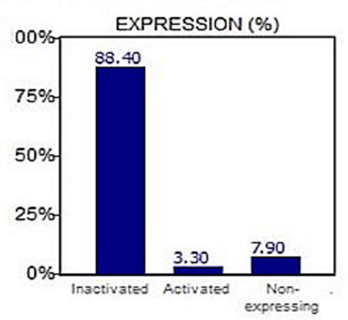

C

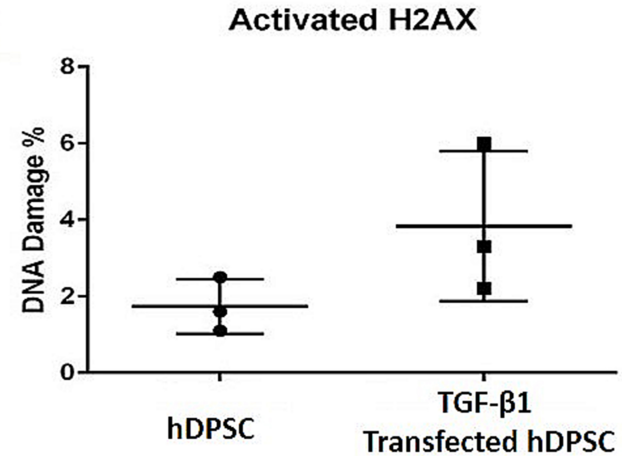

D

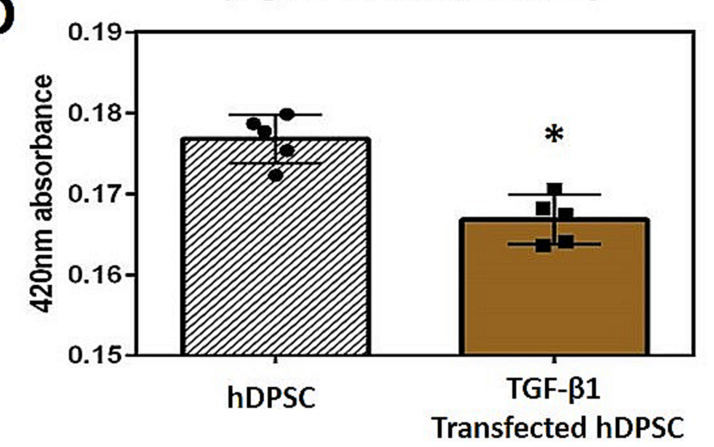

Fig. 5. TGF- $\beta 1$ gene transfection was increased the number of cells at the $S$ phase in hDPSCs, $\mathrm{p}<0.05$ (A). Electroporation performed for transfection increased DNA damage in a small amount but this was no statistically significant difference, $p>0.05$ (B, C). Cellular senescence decreased in TGF- $\beta 1$ transfected group in a statistically significant form. $\mathrm{p}<0.05$ (D).

grow MSCs in a serum-free medium up to 5 passages. $\beta$-FGF, TGF- $\beta$, and PDGF signaling is also important for MSC growth (17). Our results showed that the continuous TGF$\beta 1$ overexpression in hDPSCs did not negatively infl uence the immunophenotype and surface marker expression of MSCs. The TGF- $\beta 1$ signal pathway was shown to have a critical role in the osteogenic and chondrogenic differentiation of MSCs. TGF- $\beta 1$ is also an inhibitor of adipogenesis via SMAD 3 signaling. Our results support these data reported in the literature on TGFB1, because TGF- $\beta 1$ increased osteogenic and chondrogenic differentiation but decreased adipogenic differentiation. The activin/nodal pathway, which signals through the
TGF- $\beta 1$ pathway, cooperates with FGF signaling in maintaining the pluripotency of embryonic stem cells. We found in this study that overexpression of TGF- $\beta 1$ with gene transfer had higher proliferation rate and decreased total apoptosis in hDPSCs $(p<0.05)$; and the number of cells at " $S$ " phase was higher with TGF- $\beta 1$ transfection. However, there was no significant difference at DNA damage. Jian $\mathrm{H}$ et al. (2006) showed that TGF- $\beta 1$ revealed unique biological effects in specific cellular condition of human MSCs, as it induces the proliferation of those cells, which is in contrast to the strong antiproliferative effect of TGF- $\beta 1$ on many other cell types, suggesting that TGF- $\beta 1$ may induce particular biological 
responses through the integrated actions of $\beta$-catenin and SMAD proteins in the nucleus to regulate the expression of a specific set of TGF- $\beta 1$ target genes. TGF- $\beta$ single or in a mix with Platelet-Derived Growth Factor (PDGF) and Fibroblast Growth Factor (FGF) was suggested to be required to enable in vitro proliferation of MSCs (17-27), whereas other studies demonstrated that it induces cell-cycle arrest in mesodermal cells $(28,29)$. Some of these conflicting results may be due to the heterogeneous composition of different MSC isolation methods or culture requirement (30). In our study, we found that cellular senescence decreased in TGF- $\beta 1$ transfected group. Senescence result in a permanent cell cycle arrest and MSCs lose their self-renewal potential (21). The superior proliferative ability and regenerative potential are major phenotypes of MSCs (22). Loss of regenerative potential of MSCs would limit their practice in regenerative therapy. TGF- $\beta 1$ has been reported to induce senescence in tumor cells and other cells $(23,24)$. Wu et al. (2014) studied the effect of TGF- $\beta 1$ on senescence of BMMSCs. Their conclusion showed that treatment with TGF- $\beta 1(1 \sim 10$ $\mathrm{ng} / \mathrm{mL}$ ) increased SA-Gal activity and mtROS production in BMSCs in a dose-dependent form (31). However, Walenda et al. (2013) reported that TGF- $\beta 1$ did not stimulate early senescence. This was also evident, when they analyzed senescence-associated DNA methylation modifies. They suggested that gene expression profiles of MSCs differed remarkably at relatively early (P 3 5) and later passages (P 10). Nonetheless, they also reported that relative gene expression variations provoked by TGF- $\beta 1$ in a time course-dependent manner were very parallel in MSCs of early and late passage. These results support the idea that TGF- $\beta 1$ has great impact on MSC function and has similar molecular effects during culture expansion (25). It has been reported in previous transfection studies in the literature that transfected cells preserve the transfer efficiency even after long-term culture, and the transferred gene is expressed in a continuous manner after the gene transfer. Kim et al. (2014) studied the effect of TGF- $\beta 1$ overexpression on the chondrogenic differentiation of synovial stem cells; and the TGF- $\beta 1$ gene product was transferred into synovial stem cells through retroviral vectors. Even on day 15 after the transfer, it was shown with the ELISA test that the TGF- $\beta 1$ in the conditioned medium of the transfected cells were at high levels; and TGF- $\beta 1$ protein levels increased gradually depending on time in the culture medium. To compare the MSC surface marker expressions in TGF- $\beta 1$ transfected and non-transfected synovial fluid stem cells, long-term culture was carried out in the transfected cells for 21 days, and it was determined that the surface marker expression of the cells was not affected even on the $21^{\text {st }}$ day (32). These data support the results we obtained in the present study. In our study, it was shown by us that the MSC surface marker expressions of the TGF- $\beta 1$ transfected hDPSCs in the $3^{\text {rd }}$ passage (approximately on the $20 \sim 21^{\text {st }}$ days of the culture) were not affected in post-transfection cultures. The researchers showed that after the transfection with retroviral TGF- $\beta 1$ transfected cells, the transfected cells formed aggregates by culturing with chondrogenic medium; and even that these aggregates were larger, and differentiated more chondrogenically in the transfected cell groups (32). In our study, it was determined that the TGF$\beta 1$ transfected cells were cultured in 3 dimensional cultures for 21 days with chondrogenic induction to form aggregates; and the TGF- $\beta 1$ gene transfer increased chondrogenic differentiation in hDPSCs. In a study reporting that TGF- $\beta 1$ overexpression triggered homing in BMMSCs in renal ischemia-reperfusion injury, the TGF$\beta 1$ plasmid was transfected into BMMSCs with lentiviral vectors; and the Fluorescent Method was used to determine the transfection efficacy 48 hours after the transfection (33). In our study, the TGF- $\beta 1$ plasmid was transferred to hDPSCs with electroporation; and the transfection efficacy was measured with flow cytometry at the $48^{\text {th }}$ hour as $95 \%$. It was determined with western blot analysis that the TGF- $\beta 1$ protein expression increased at a significant level on the $3^{\text {rd }}$ and $6^{\text {th }}$ days compared to non-transfected DPSCs; and the measurements of western blot analysis were supported by the flow cytometry. In addition, the transfection success was shown by us under fluorescence microscope with the transfer of the GFP plasmid to the cells. These reports in the literature about the stability of the gene that is transferred and the culture conditions after the transfection support the results of our study. It was also shown in our study with flow cytometry, western blot, CFU-F, hygromycin resistance, and surface marker expression multilineage differentiation tests that long-term gene transfer stability is obtained in cells. In a study in which transfection parameters were optimized with electroporation in DPSCs the transfection efficiency was measured with the flow cytometry and western blot analysis at the $48^{\text {th }}$ and $72^{\text {nd }}$ hours (10). The findings we mentioned in the study showing that the MSC surface marker expressions were not affected after the transfection were supported in the study conducted by Rizk et al. by showing that CD44 was positively expressed in TGF- $\beta 3$ transfected cells and CD45 was negatively expressed (10). These results show that TGF- $\beta$ transfection affect the MSC surface markers. This situation shows that we pro- 
Table 1. This table shown that results statistically of viability, apoptosis, Cell cycle, DNA damage and senescence assay

\begin{tabular}{lcccc}
\hline \multicolumn{1}{c}{ Experiments } & $\begin{array}{c}\text { Avarege } \pm \text { SD } \\
\text { (hDPSCs) }\end{array}$ & $\begin{array}{c}\text { Avarege } \pm \text { SD } \\
\text { transfected hDPSCs) }\end{array}$ & $\begin{array}{c}\text { Number of } \\
\text { values }\end{array}$ & p-value \\
\hline Viability & $92.42 \pm 0.2682$ & $94.97 \pm 0.1202$ & 3 & 0.0005 \\
Early Apoptosis & $4.267 \pm 0.2048$ & $2.267 \pm 0.01667$ & 3 & 0.0006 \\
Late Apoptosis & $3.250 \pm 0.1041$ & $2.633 \pm 0.1014$ & 3 & 0.0132 \\
Total Apoptosis & $7.467 \pm 0.2048$ & $4.900 \pm 0.1155$ & 3 & 0.0004 \\
Cell Cycle (S phase) & $31.27+0.8192$ & $34.70+0.6658$ & 3 & 0.0313 \\
DNA Damage & $1.733 \pm 0.4096$ & $2.733 \pm 0.2963$ & 3 & 0.1191 \\
Senescence & $0.1768 \pm 0.001345$ & $0.1668 \pm 0.001363$ & 5 & 0.0008 \\
\hline
\end{tabular}

duced cells, which can better differentiate without impairing the immunophenotype, which affect their biological characteristics better, and which have better usage and yield potential in terms of regenerative medicine. In our study, there is hygromycin $\mathrm{b}$ resistance gene area as the eukaryotic selective marker in the plasmid which was transfected. The TGF- $\beta 1$ transfected cells were used to guarantee the permanent integration of the transferred gene (to which hygromycin $\mathrm{b}$ antibiotic was transferred) to the chromosome in the complete medium at $50 \mu \mathrm{g} / \mathrm{ml}$ in the culture medium; and the experiments were established with the hDPSC, which received the TGF- $\beta 1$ gene permanently. Liu et al. conducted a study and also reported that the long-term culture after transfection did not affect the cells negatively, and the stability of the transferred gene was ensured. The researchers transferred the Brain-Derived Neurotrophic Factor Gene (BDNF) to the cells with transfection in the differentiation of bone marrow-derived mesenchymal stem cells into nerve-like cells. Since the transferred plasmid geneticin (G418) has a selective marker, the cells were selected for 14 days with selective antibiotics as in our experiment plan. The ELISA test results showed that the BDNF gene product that was transferred was at high levels even after 2 months in cell supernatants (34). The long-term culture conditions of the transfected cells show that they do not affect them negatively, which was also the case in our study. It was reported by Kim et al. that TGF- $\beta 1$ transfection not only increased the chondrogenesis but also increased the proliferation in MSCs (32). In our study, the TGF- $\beta 1$ transfection increased the proliferation in hDPSCs at a significant level. Despite these studies, which we mentioned as being associated with TGF- $\beta 1$ transfection in the literature, there are no comprehensive studies conducted on how the TGF- $\beta 1$ transfection affects the MSCs cell characteristics. The existing studies remain at proliferation and multilineage differentiation level. Moreover, the variables such as cell cycle, DNA damage and cellular senescence of the Dental Pulp Mesenchymal Stromal Cells after TGF- $\beta 1$ overexpression were investigated in our study. The present study of ours showed that TGF- $\beta 1$ overexpression affect Dental Pulp Mesenchymal Stromal Cells in a positive way. These results reflect that TGF- $\beta 1$ has major impact on MSC differentiation. TGF- $\beta 1$ transfection has no effect on cell surface markers. TGF- $\beta 1$ transfection has positive effects on proliferation, cell cycle and prevents cellular senescence and apoptosis (Table 1). In further studies, it will be essential to determine whether TGF- $\beta 1$ can play a role in attempts to use MSC for therapeutic approaches. With this study, cells were produced with increased differentiation potentials and strengthened biological features that may be used in regenerative medicine, tissue engineering, gene therapy and cellular therapy studies.

\section{Acknowledgments}

The authors would like to thank Erciyes University, Betul Ziya Eren Genome and Stem Cell Center (GEN$\mathrm{KOK})$, Kayseri-Turkey because of the facilities they provided. This study was presented as a poster in $1^{\text {st }}$ International Cell Death and Research Congress, 2016, Izmir, Turkey.

\section{Potential Conflict of Interest}

The authors have no conflicting financial interest.

\section{References}

1. Zhang F, Hong Y, Liang W, Ren T, Jing S, Lin J. Co-culture with Sertoli cells promotes proliferation and migration of umbilical cord mesenchymal stem cells. Biochem Biophys Res Commun 2012;427:86-90

2. Ferroni L, Gardin C, Tocco I, Epis R, Casadei A, Vindigni V, Mucci G, Zavan B. Potential for neural differentiation of mesenchymal stem cells. Adv Biochem Eng Biotechnol 2013;129:89-115

3. Patel DM, Shah J, Srivastava AS. Therapeutic potential of 
mesenchymal stem cells in regenerative medicine. Stem Cells Int 2013;2013. doi: 10.1155/2013/496218

4. Karaöz E, Doğan BN, Aksoy A, Gacar G, Akyüz S, Ayhan S, Genç ZS, Yürüker S, Duruksu G, Demircan PC, Sariboyaci AE. Isolation and in vitro characterisation of dental pulp stem cells from natal teeth. Histochem Cell Biol 2010;133:95-112

5. Gronthos S, Mankani M, Brahim J, Robey PG, Shi S. Postnatal human dental pulp stem cells (DPSCs) in vitro and in vivo. Proc Natl Acad Sci U S A 2000;97:13625-13630

6. Miura M, Gronthos S, Zhao M, Lu B, Fisher LW, Robey PG, Shi S. SHED: stem cells from human exfoliated deciduous teeth. Proc Natl Acad Sci U S A 2003;100:5807-5812

7. d'Aquino R, Graziano A, Sampaolesi M, Laino G, Pirozzi G, De Rosa A, Papaccio G. Human postnatal dental pulp cells co-differentiate into osteoblasts and endotheliocytes: a pivotal synergy leading to adult bone tissue formation. Cell Death Differ 2007;14:1162-1171

8. Alge DL, Zhou D, Adams LL, Wyss BK, Shadday MD, Woods EJ, Gabriel Chu TM, Goebel WS. Donor-matched comparison of dental pulp stem cells and bone marrow-derived mesenchymal stem cells in a rat model. J Tissue Eng Regen Med 2010;4:73-81

9. Huang GT, Gronthos S, Shi S. Mesenchymal stem cells derived from dental tissues vs. those from other sources: their biology and role in regenerative medicine. J Dent Res 2009;88:792-806

10. Rizk A, Rabie BM. Electroporation for transfection and differentiation of dental pulp stem cells. Biores Open Access 2013;2:155-162

11. Liang YY, Brunicardi FC, Lin X. Smad3 mediates immediate early induction of Idl by TGF-beta. Cell Res 2009;19: 140-148

12. Massagué J. How cells read TGF-beta signals. Nat Rev Mol Cell Biol 2000;1:169-178

13. Moustakas A, Heldin CH. Non-Smad TGF-beta signals. J Cell Sci 2005;118:3573-3584

14. Siegel PM, Massagué J. Cytostatic and apoptotic actions of TGF-beta in homeostasis and cancer. Nat Rev Cancer 2003; 3:807-821

15. Frippiat C, Chen QM, Zdanov S, Magalhaes JP, Remacle J, Toussaint O. Subcytotoxic $\mathrm{H} 2 \mathrm{O} 2$ stress triggers a release of transforming growth factor-beta 1, which induces biomarkers of cellular senescence of human diploid fibroblasts. J Biol Chem 2001;276:2531-2537

16. Park JS, Chu JS, Tsou AD, Diop R, Tang Z, Wang A, Li $S$. The effect of matrix stiffness on the differentiation of mesenchymal stem cells in response to TGF- $\beta$. Biomaterials 2011;32:3921-3930

17. Ng F, Boucher S, Koh S, Sastry KS, Chase L, Lakshmipathy U, Choong C, Yang Z, Vemuri MC, Rao MS, Tanavde V. PDGF, TGF-beta, and FGF signaling is important for differentiation and growth of mesenchymal stem cells (MSCs): transcriptional profiling can identify markers and signaling pathways important in differentiation of MSCs into adipogenic, chondrogenic, and os- teogenic lineages. Blood 2008;112:295-307

18. Bakin AV, Tomlinson AK, Bhowmick NA, Moses HL, Arteaga CL. Phosphatidylinositol 3-kinase function is required for transforming growth factor beta-mediated epithelial to mesenchymal transition and cell migration. J Biol Chem 2000;275:36803-36810

19. Carr BI, Hayashi I, Branum EL, Moses HL. Inhibition of DNA synthesis in rat hepatocytes by platelet-derived type beta transforming growth factor. Cancer Res 1986;46:23302334

20. Principe DR, Doll JA, Bauer J, Jung B, Munshi HG, Bartholin L, Pasche B, Lee C, Grippo PJ. TGF- $\beta$ : duality of function between tumor prevention and carcinogenesis. J Natl Cancer Inst 2014;106. doi: 10.1093/jnci/djt369

21. Burova E, Borodkina A, Shatrova A, Nikolsky N. Sublethal oxidative stress induces the premature senescence of human mesenchymal stem cells derived from endometrium. Oxid Med Cell Longev 2013;2013. doi: 10.1155/2013/474931

22. Sarugaser R, Hanoun L, Keating A, Stanford WL, Davies JE. Human mesenchymal stem cells self-renew and differentiate according to a deterministic hierarchy. PLoS One 2009;4. doi: 10.1371/journal.pone.0006498

23. Senturk S, Mumcuoglu M, Gursoy-Yuzugullu O, Cingoz B, Akcali KC, Ozturk M. Transforming growth factor-beta induces senescence in hepatocellular carcinoma cells and inhibits tumor growth. Hepatology 2010;52:966-974

24. Yu AL, Birke K, Moriniere J, Welge-Lüssen U. TGF\{beta\}2 induces senescence-associated changes in human trabecular meshwork cells. Invest Ophthalmol Vis Sci 2010; 51:5718-5723

25. Walenda G, Abnaof K, Joussen S, Meurer S, Smeets H, Rath B, Hoffmann K, Fröhlich H, Zenke M, Weiskirchen $\mathrm{R}$, Wagner W. TGF-betal does not induce senescence of multipotent mesenchymal stromal cells and has similar effects in early and late passages. PLoS One 2013;8. doi: 10.1371/journal.pone.0077656

26. Akpinar G, Kasap M, Aksoy A, Duruksu G, Gacar G, Karaoz E. Phenotypic and proteomic characteristics of human dental pulp derived mesenchymal stem cells from a natal, an exfoliated deciduous, and an impacted third molar tooth. Stem Cells Int 2014;2014. doi: 10.1155/2014/ 457059

27. Jian H, Shen X, Liu I, Semenov M, He X, Wang XF. Smad3-dependent nuclear translocation of beta-catenin is required for TGF-betal-induced proliferation of bone marrow-derived adult human mesenchymal stem cells. Genes Dev 2006;20:666-674

28. Ito T, Sawada R, Fujiwara Y, Seyama Y, Tsuchiya T. FGF-2 suppresses cellular senescence of human mesenchymal stem cells by down-regulation of TGF-beta2. Biochem Biophys Res Commun 2007;359:108-114

29. Debacq-Chainiaux F, Borlon C, Pascal T, Royer V, Eliaers F, Ninane N, Carrard G, Friguet B, de Longueville F, Boffe $\mathrm{S}$, Remacle J, Toussaint O. Repeated exposure of human skin fibroblasts to UVB at subcytotoxic level triggers premature senescence through the TGF-betal signaling path- 
way. J Cell Sci 2005;118:743-758

30. Wagner W, Ho AD. Mesenchymal stem cell preparations-comparing apples and oranges. Stem Cell Rev 2007;3: 239-248

31. Wu J, Niu J, Li X, Wang X, Guo Z, Zhang F. TGF- $\beta 1$ induces senescence of bone marrow mesenchymal stem cells via increase of mitochondrial ROS production. BMC Dev Biol 2014;14:21

32. Kim YI, Ryu JS, Yeo JE, Choi YJ, Kim YS, Ko K, Koh YG. Overexpression of TGF- $\beta 1$ enhances chondrogenic differentiation and proliferation of human synovium- de- rived stem cells. Biochem Biophys Res Commun 2014;450: 1593-1599

33. Si X, Liu X, Li J, Wu X. Transforming growth factor- $\beta 1$ promotes homing of bone marrow mesenchymal stem cells in renal ischemia-reperfusion injury. Int J Clin Exp Pathol 2015;8:12368-12378

34. Liu Q, Cheng G, Wang Z, Zhan S, Xiong B, Zhao X. Bone marrow-derived mesenchymal stem cells differentiate into nerve-like cells in vitro after transfection with brain-derived neurotrophic factor gene. In Vitro Cell Dev Biol Anim 2015;51:319-327 